\title{
Educational Intervention on Social Media To Prevent Occupational Neck Pain; A Protocol for a Randomized Trial To Prevention Occupational Neck Pain in Teachers Profession
}

\section{Sedigheh Sadat Tavafian ( $\nabla$ tavafian@modares.ac.ir)}

Tarbiat Modares University Faculty of Medical Sciences

\section{Zohre Moradi}

Tarbiat Modares University Faculty of Medical Sciences

\section{Seyedeh Somayeh Kazemi}

Mazandaran University of Medical Sciences Faculty of Medicine

\section{Research Article}

Keywords: Job-related neck pain, social media, teacher, disability

Posted Date: December 1st, 2021

DOI: https://doi.org/10.21203/rs.3.rs-915848/v1

License: (c) (1) This work is licensed under a Creative Commons Attribution 4.0 International License.

Read Full License 


\section{Abstract}

Background: Neck pain is one of the most common work-related musculoskeletal disorders (WMSDs). Which has important social and economic consequences such as reduced productivity due to absenteeism, leave and early retirement and financial losses due to medical expenses for the workforce, especially teachers, and is a serious problem among teachers. This study aims was to evaluate whether a theory-based intervention social media could change the high-risk behaviors that cause to job-related neck pain among teachers.

Methods: This is a community-randomized controlled trial that will be done in three steps. The stages of the study include: The first stage is a qualitative study to obtain the items and areas of the researchermade questionnaire based on the health belief model (HBM), the second stage is the psychometric evaluation of the questionnaire and the third stage is the design and implementation of model-based educational intervention in social media. The study population is middle school teachers in the 19th district of Tehran, which are randomly divided into two groups of intervention and control. The intervention group receives training packages on social media and the control group does not receive any training. The intervention tries to improve the knowledge, attitude, skills and self-efficacy in adopting neck pain prevention behaviors among teachers. The study will also assess whether the intervention can reduce disability caused by neck pain among teachers.

Discussion: Job-related neck pain can have a negative impact on teachers' health. This study is an attempt to investigate the impact, development and implementation of interventions in reducing jobrelated neck pain on social media.

Trial registration number: IRCT20210301050542N1

Registered on 16 March 2021 in IRCT (Iranian registry of Clinical Trial

Ethics Code: IR.MODARES.REC.1399.163

\section{Background}

Work-related musculoskeletal disorders (WMSDs) are one of the largest occupational health problems in the working population in developing and developed countries, with the highest number of occupational complaints [1]. These disorders can progress from weak to severe [2] and have important social and economic consequences for the workforce [3,4]. Performing work tasks in inappropriate physical, psychological and ergonomic conditions causes disorders in the bones, nerves, tendons, ligaments, muscles and blood vessels and causes pain in the neck, back, shoulders, elbows, wrists, arms and hands [5-7]. About $44 \%$ of all occupational diseases are musculoskeletal disorders caused by WMSDs [8]. Neck pain is one of the most common and costly health challenges in the workplace $[9,10]$. That affects $52-$ $58 \%$ of the population during life [8]. Neck pain (NP) has a significant impact on social functioning, health status and quality of life and leads to reduced quality of life, inability to perform activities and 
impose health costs on society and governments $[11,12]$. The prevalence of neck pain is higher in some professions than in others $[1,13]$. For example, the prevalence of neck pain among teachers is the fourth health problem, accounting for 44 to $61 \%$ of injuries $[3,14]$. Teachers have been shown to have a higher percentage of work-related musculoskeletal disorders than other occupations 39 to $95 \%[1,2,6]$. The annual prevalence rate of neck pain among teachers is reported to be $57.8 \%$ [12]. Neck pain in teachers is caused by several reasons such as age, gender, duration of employment, use of inappropriate body postures, uncontrolled stress, high workload, prolonged sitting and standing, job dissatisfaction and doing monotonous and repetitive tasks [4,15-17]. The effects of neck pain on teachers include frequent leave and absences, reduced individual and social functioning, early retirement, inability to perform activities, and the imposition of health costs [18]. Various factors such as demographic factors (body mass index, vitamin D deficiency), physical factors (excessive computer use, prolonged sitting and standing, excessive bending of the trunk, squatting, bending over neck forward or backward, keeping hands above shoulder level for a long time, doing strenuous activities and unprincipled exercise at work or outside, lack of adequate rest time during working hours), Psychological factors (general health, workrelated stress, lack of attention and support from colleagues, marital and family relationships, job dissatisfaction, weak interpersonal relationships, organizational characteristics and financial - social aspects) cause neck pain [19-21]. Although various factors cause neck pain, but one of the most important causes of neck pain in teachers is behavioral factors [11, 12, 22, 23]. Reducing neck pain was possible if teachers could observe and maintain correct behaviors during work and activity [7, 24]. It seems that the main obstacles in teaching correct behaviors to teachers are lack of time required for onthe-job training, lack of ergonomic equipment in the workplace, lack of adequate rest time at work and health care costs[22]. A model-based educational intervention on social media can overcome these limitations. Numerous studies show that the effect of model-based educational interventions on reducing musculoskeletal disorders is much greater than non-model interventions $[20,25,26]$. Therefore, we decided to examine the behavioral factors that cause neck pain in teachers, and based on that, to design, develop and implement an intervention based on the Health Belief Model (HBM). One of the best effective models in health education in promoting preventive behaviors is the health belief model [27]. According to this model, a person changes behavior when he understands the degree of danger that threatens him (perceived sensitivity and severity) and also has a proper assessment of the barriers and benefits of health behaviors (perceived barriers and benefits) [28]. To adopt disease-preventing behaviors, people must first feel threatened (perceived sensitivity), then understand the severity of the complications (perceived severity), the positive signals they receive from the environment (Cues to action), believe in the usefulness of the behavior (perceived benefits), understand the low cost of performing the behavior (perceived barriers) and be able to perform preventive behaviors (self-efficacy) to finally act properly in preventing the disease (Fig. 1) [25]. Therefore, the reason for using this model to develop and implement intervention in social media is to prevent and reduce neck pain in teachers due to the multidimensional nature of job-related neck pain. This study tries to identify the factors that are effective in promoting jobrelated neck pain-reducing behaviors among teachers. Another reason for using the health belief model is its unique ability to design and implement educational interventions in the workplace, that has been the basis of many educational and health interventions in health to change behavior in recent decades [25, 
26]. Numerous studies have shown the effect of educational interventions based on health belief model on disease protection behaviors, behavior modification and promotion of behaviors that reduce musculoskeletal disorders such as low back pain, neck and shoulder pain [29-31]. There is currently no study that shows the effect of educational interventions based on the health belief model on the prevention and reduction of neck pain among teachers. The overall purpose of this study is to design and develop an intervention based on the Health Belief Model in social media in order to prevent job-related neck pain among school teachers.

\section{Methods/design}

This study is a randomized controlled trial. The overall purpose is to study, develop and evaluate an intervention of model-based in social media to reduce job neck pain in school teachers. The study consists of three stages ( Table 1): The first phase of the research will be a qualitative study on 25 teachers. Criteria for entering this stage of the research: having a teaching job, having conscious satisfaction, having a job-related neck pain experience, willingness and ability to transfer experiences and diversity of research (education, gender, age, work experience). Data collection will be done through telephone calls and semi-structured interviews by the researcher with the participants. The questions will be designed based on the structures of the health belief model. Participants are asked questions about their experiences with job-related neck pain, its consequences and effects on work and life, the extent to which teachers suffer from neck pain, and the factors that affect neck pain prevention. Based on the analysis of the data obtained from the interview, items, sub-categories and main categories of the researcher-made questionnaire are prepared and compiled. The second stage of psychometrics is a researcher-made questionnaire. In this stage: the researcher-made questionnaire will be subject to content validity and face validity by 15 specialists in health education and health promotion, ergonomics, physiotherapy and occupational health. Exploratory factor analysis and scale correlation matrix will also be used to evaluate the construct validity and obtain the final items of the questionnaire. The third stage of the study includes: designing, developing and implementing an educational intervention based on the health belief model ( Fig. 2). At this stage, a list of all 26 schools in District 19 will be prepared. From schools, people are randomly selected and then randomly divided into two groups of intervention and control. The intervention group receives a training program while the control group does not receive any training program. Participants are evaluated in three stages of time: in the previous stage, one and three months after the intervention. The study environment will be public schools in the 19th district of Tehran province. Participants are junior high school teachers. Inclusion criteria in this study: Willingness to participate in study, access to the Internet and having the skills to use the Internet. Exclusion criteria include: unwillingness to continue to participate in research, having a second job, having congenital musculoskeletal disorders related to the neck, history of surgery, neck vertebral fractures and significant neck pain unrelated to the job, medical prohibition in Especially doing sports. The main purpose of this study is to prevent and reduce occupational neck pain in teachers, so we will identify the factors and behavioral factors that cause neck pain. And to promote neck pain prevention behaviors, we will design an educational intervention based on the Health Belief Model. The findings of this stage will be obtained 
through semi-structured interviews based on the Health Belief Model. Based on this, we can determine the factors affecting neck pain, the correction of which leads to change and continuity of behavior. These factors include: perceived sensitivity, perceived severity, perceived benefits, perceived barriers, Cues to action, and self-efficacy [31]. Based on the evaluation of the extent of each of these factors, it is possible to implement an intervention to change behavior. Educational content includes: definition of occupational neck pain and its causes, benefits of health behaviors, strategies to deal with barriers to neck pain prevention behaviors, improving self-efficacy in adopting and performing neck pain prevention behaviors, stressors in the workplace, the effect of stress On neck pain, stress management and control techniques, effective communication, anger management skills, excitement, ergonomic principles on neck pain prevention, corrective movements that reduce neck pain, stretching movements that strengthen neck muscles, how to sleep properly, how to Proper sitting and standing, correct posture when working with computer and telephone and doing daily chores. The educational content will be described based on evidence and using understandable language. Participants can communicate with the researcher by email and phone call. The intervention group will receive training in the form of webinars, group discussions, questions and answers, videos, animations, posters, pamphlets and infographics. How to receive training is supervised by the researcher. The trainings will be provided to the intervention group through social media for one month.

After that, reminder trainings will be provided to the intervention group for three months. During this period, the control group will not receive any intervention and after the intervention, the training package will be provided to the control group. The main outcome is the promotion of neck pain prevention behaviors that are assessed using a researcher-made questionnaire. Data collection instrument is a researcher-made questionnaire that is completed and collected in three stages, before, one and three months after the intervention. Questionnaires are completed anonymously to gain participants' trust in the intervention. The questionnaire based on the health belief model will have different domains (knowledge, perceived sensitivity, perceived severity, perceived barriers, perceived benefits, Cues to action, self-efficacy and behavior). Knowledge questions from the Likert three-part spectrum are true (2), no idea (1), wrong (0) and domain questions (perceived sensitivity and intensity, perceived barriers and benefits, self-efficacy and Cues to action) as spectrum 5 parts like, (completely agree 5), (agree 4), (no idea 3), (disagree 2) and (completely disagree 1) will be considered. Behavior questions are considered as a fivepart Likert scale (never 1), (rarely 2), (sometimes 3), (often 4), (always 5). This questionnaire measures the variables of knowledge, attitude, perceived threat, self-efficacy, reinforcing factor and barriers to behavior and behavior. A higher score in each area of the questionnaire will indicate a better situation. This study will be conducted with power of $80 \%$ and $5 \%$ significance level. The sample size will be considered $10 \%$ drop,73 people are estimated for each group. In total, the number of participants in the study will be 146 people. For randomization, first a list of teachers' telephone numbers with a specific code is prepared and the codes are poured into a bag and randomly divided into two groups of intervention and control. This study is a double-blind study and the researcher and participants are not aware of it. 


\section{Statistical Analysis}

The data obtained from the qualitative study will be analyzed based on Graneheim and Landman algorithms in qualitative content analysis. MAXQDA software will be used to encode semi-structured interview data. To evaluate the validity of the structure, factor analysis and scale correlation matrix and the Kaiser_ Meyer_ Olkin (KMO) Index and Bartlett's test sphericity will be used. The factor structure of the questionnaire is extracted using Varimax rotation. The quantitative data will be analyzed using SPSS V24. Descriptive statistics will include frequencies, means, and standard deviations. The KolmogorovSmirnov test will be used to check the normal distribution of data. Also, to compare the means between the two intervention and control groups of the test Independent-Samples T Test will be used. Paired t-test will be used to compare the means in each group at two points in time and ANOVA test will be used to compare the means in each group at three points in time. To analyze and evaluate the correlation between demographic variables, we will use correlation tests (Pearson for parametric data) and (Spearman or Kendall for non-parametric data) and Chi-square test.

\section{Discussion}

One of the features of this study is paying attention to promoting health in the workplace. This study will investigate the effect of interventions in preventing and reducing occupational neck pain among teachers. The main framework of this study will be to design a model-based intervention based on evidence on social media to prevent teachers' neck pain.

Strengths of this study include conducting a qualitative study to design a researcher-made questionnaire, psychometric phase of the questionnaire, designing an educational intervention based on the HBM model, planning and implementing a specific intervention and having a control group, using social media with flexibility and accessibility Makes it easy for users to access educational content.

One of the weaknesses of the study is the self-report of people about neck pain. Another limitation of the study is the lack of time for 6- and 12-month follow-up to determine: Will the effect of the interventions be maintained for a long time or not?

\section{Declarations}

\section{Author contributions}

Zohreh Moradi was the main investigator, collected and analyzed the data, and wrote the first draft. Sedigheh Sadat Tavafian supervised the study and contributed to the writing process. Seyedeh Somayeh Kazemi was the study advisor, contributed to analysis and interpretation, and provided the final draft. All authors read and approved the final manuscript.

\section{Acknowledgments}


This paper is extracted from the master's thesis, Department of Health Education and Promotion, Faculty of Medical Sciences, Tarbiat Modares University, Tehran, Iran. The authors thank the teachers, principals and staff of administrative units, principals and education officials of Tehran's 19th district.

\section{Funding Statement}

This research received no specific grant from any funding agency in the public, commercial, or not-forprofit sectors.

\section{Data Availability Statement}

The data will be available from the corresponding author on request

\section{Conflicts of interests}

No conflict of interest has been declared by the authors.

\section{Ethical considerations}

The written informed consent was obtained from each participant. The Ethics committee of Tarbiat Modares University, Tehran, Iran. The ethical code is (IR.MODARES.REC.1399.163).

\section{Ethics Permission}

The Tarbiat Modares University of Ethics Committee for Health Research Ethics (IR.MODARES.REC.1399.163) approved the study. Informed consent will be obtained from all participants. The data (when ready) will be available from the corresponding author on request.

\section{Consent for publication}

Not applicable.

\section{References}

1. Niciejewska M, Kasian S. Musculoskeletal disorders related to the professional work of academic teachers and the quality of their work. Quality Production Improvement-QPI. 2019;1:47-54.

2. MM K. Work related musculoskeletal disorders among preparatory school teachers in Egypt. Egyptian Journal of Occupational Medicine. 2017;41:115-26.

3. Damayanti S, Zorem M, Pankaj B. Occurrence of Work Related Musculoskeletal Disorders among School Teachers in Eastern and Northeastern Part of India. International Journal of Musculoskeletal Pain Prevention. 2017;2:187-92.

4. Babamiri M, Heidarimoghadam R, Saidnia H, Mohammadi Y, Joudaki J. Investigation of the Role of Mental Workload, Fatigue, and Sleep Quality in the Development of Musculoskeletal Disorders. Journal of Occupational Hygiene Engineering Volume. 2019;5:1-7. 
5. Ndonye NA, Matara NJ, Muriithi IA. Predictors of Work-Related Musculoskeletal Disorders among Primary School Teachers in Machakos County, Kenya, 2019.

6. Solis-Soto MT, Schön A, Solis-Soto A, Parra M, Radon K. Prevalence of musculoskeletal disorders among school teachers from urban and rural areas in Chuquisaca, Bolivia: a cross-sectional study. BMC Musculoskelet Disord. 2017;18:425.

7. Bandpei MAM, Ehsani F, Behtash H, Ghanipour M. Occupational low back pain in primary and high school teachers: prevalence and associated factors. J Manipulative Physiol Ther. 2014;37:702-8.

8. Verma R, Madhavi K. The Effect of Postural Education on Decreasing the Severity of Neck Pain in Female School Teachers: A Prospective Cohort Study. International Journal of Therapies Rehabilitation Research. 2017;6:24.

9. Misailidou V, Malliou P, Beneka A, Karagiannidis A, Godolias G. Assessment of patients with neck pain: a review of definitions, selection criteria, and measurement tools. Journal of chiropractic medicine. 2010;9:49-59.

10. Jahre H, Grotle M, Smedbråten K, Dunn KM, Øiestad BE. Risk factors for non-specific neck pain in young adults. A systematic review. BMC Musculoskelet Disord. 2020;21:1-12.

11. Ehsani F, Mohseni-Bandpei MA, Fernández-De-Las-Peñas C, Javanshir K. Neck pain in Iranian school teachers: Prevalence and risk factors. J Bodyw Mov Ther. 2018;22:64-8.

12. Temesgen MH, Belay GJ, Gelaw AY, Janakiraman B, Animut Y. Burden of shoulder and/neck pain among school teachers in Ethiopia. BMC Musculoskelet Disord. 2019;20:18.

13. Lubkowska W, editor The potential of computer software that supports the diagnosis of workplace ergonomics in shaping health awareness. AIP Conference Proceedings, 2017: AIP Publishing LLC.

14. Yue P, Liu F, Li L. Neck/shoulder pain and low back pain among school teachers in China, prevalence and risk factors. BMC Public Health. 2012;12:1-8.

15. Maghsoudian L. Ergonomic assessment of musculoskeletal disorders risk factors in office staff using ROSA method and Its relation with efficiency. Journal of Military Medicine. 2017;19:31-9.

16. Anuar NFM, Rasdi I, Saliluddin SM, Abidin EZ. Work task and job satisfaction predicting low back pain among secondary school teachers in Putrajaya. Iranian Journal of Public Health. 2016;45:8592.

17. Chaiklieng S, Suggaravetsiri P. Risk factors for repetitive strain injuries among school teachers in Thailand. Work. 2012;41:2510-5.

18. Abe T, Kamada M, Kitayuguchi J, Okada S, Mutoh Y, Uchio Y. Is being a regular player with fewer teammates associated with musculoskeletal pain in youth team sports? A cross-sectional study. BMC Musculoskelet Disord. 2017;18:105.

19. Lanhers C, Pereira B, Garde G, Maublant C, Dutheil F, Coudeyre E. Evaluation of 'I-Preventive': a digital preventive tool for musculoskeletal disorders in computer workers-a pilot cluster randomised trial. BMJ open, 2016;6. 
20. Chan C, Ackermann B. Evidence-informed physical therapy management of performance-related musculoskeletal disorders in musicians. Frontiers in psychology. 2014;5:706.

21. Shuai J, Yue P, Li L, Liu F, Wang S. Assessing the effects of an educational program for the prevention of work-related musculoskeletal disorders among school teachers. BMC Public Health. 2014;14:1211.

22. Erick $P$, Smith D. Musculoskeletal disorder risk factors in the teaching profession: a critical review. OA Musculoskelet Med. 2013;1:29.

23. Erick PN, Smith DR. A systematic review of musculoskeletal disorders among school teachers. BMC Musculoskelet Disord. 2011;12:260.

24. Arvidsson I, Simonsen JG, Dahlqvist C, Axmon A, Karlson`B, Björk J, et al. Cross-sectional associations between occupational factors and musculoskeletal pain in women teachers, nurses and sonographers. BMC Musculoskelet Disord. 2016;17:35.

25. Glanz K, Rimer BK, Viswanath K. Health behavior: Theory, research, and practice: John Wiley \& Sons;5ned Edition. San Francisco: Jossey-Bass; 2015.

26. Jeihooni AK, Askari A, Kashfi SM, Khiyali Z, Kashfi SH, Safari O, et al. Application of health belief model in prevention of osteoporosis among primary school girl students. International Journal of Pediatrics-Mashhad. 2017;5:6017-29.

27. Solhi M, Haghighi M, Rahmati Najarkolaei F, Zemestani A. HIV prevention perception among barbers according to health belief model case study from Marand. Journal of Research Health. 2014;4:5928.

28. Norozi E, Malakimoghadam H. Factors affecting arthritis preventive behavior in middle-aged women in Birjand using the Health Belief Model. Journal of Birjand University of Medical Sciences. 2018;25:334-41.

29. Lentz TA, Harman JS, Marlow NM, George SZ. Application of a value model for the prevention and management of chronic musculoskeletal pain by physical therapists. Physical therapy. 2017;97:354-64.

30. Sharafkhani N, Khorsandi M, Shamsi M, Ranjbaran M. The effect of an educational intervention program on the adoption of low back pain preventive behaviors in nurses: an application of the health belief model. Global spine journal. 2016;6:29-34.

31. Peterson CL, Evans KD, Axiotis IR. Sonographer scanning practices and musculoskeletal injury: evaluation of an occupational health issue using the health belief model. Journal of Diagnostic Medical Sonography. 2017;33:412-8.

\section{Tables}

Due to technical limitations, table 1 is only available as a download in the Supplemental Files section.

\section{Figures}




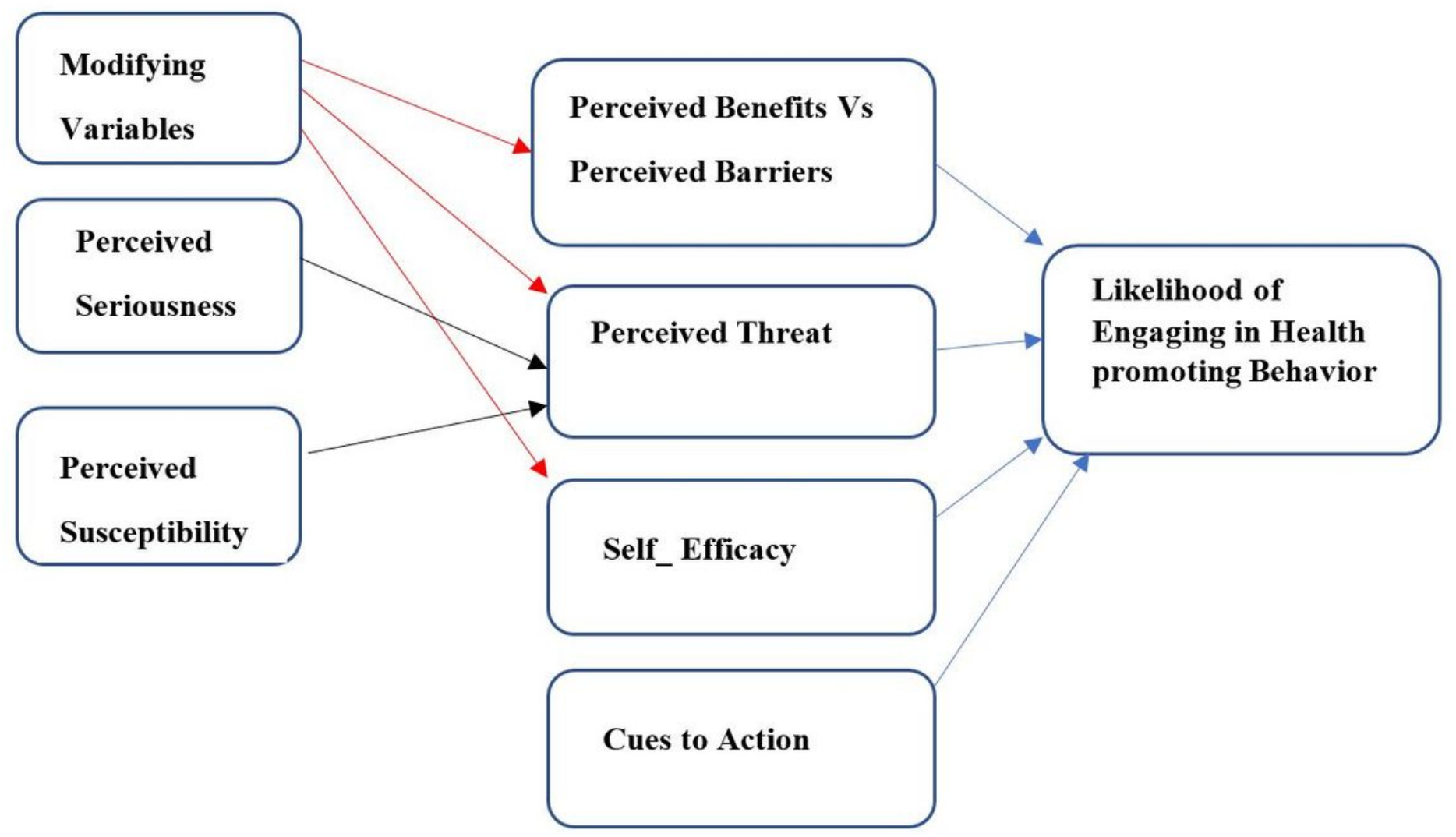

Figure 1

The constructs of Health Belief Mode 


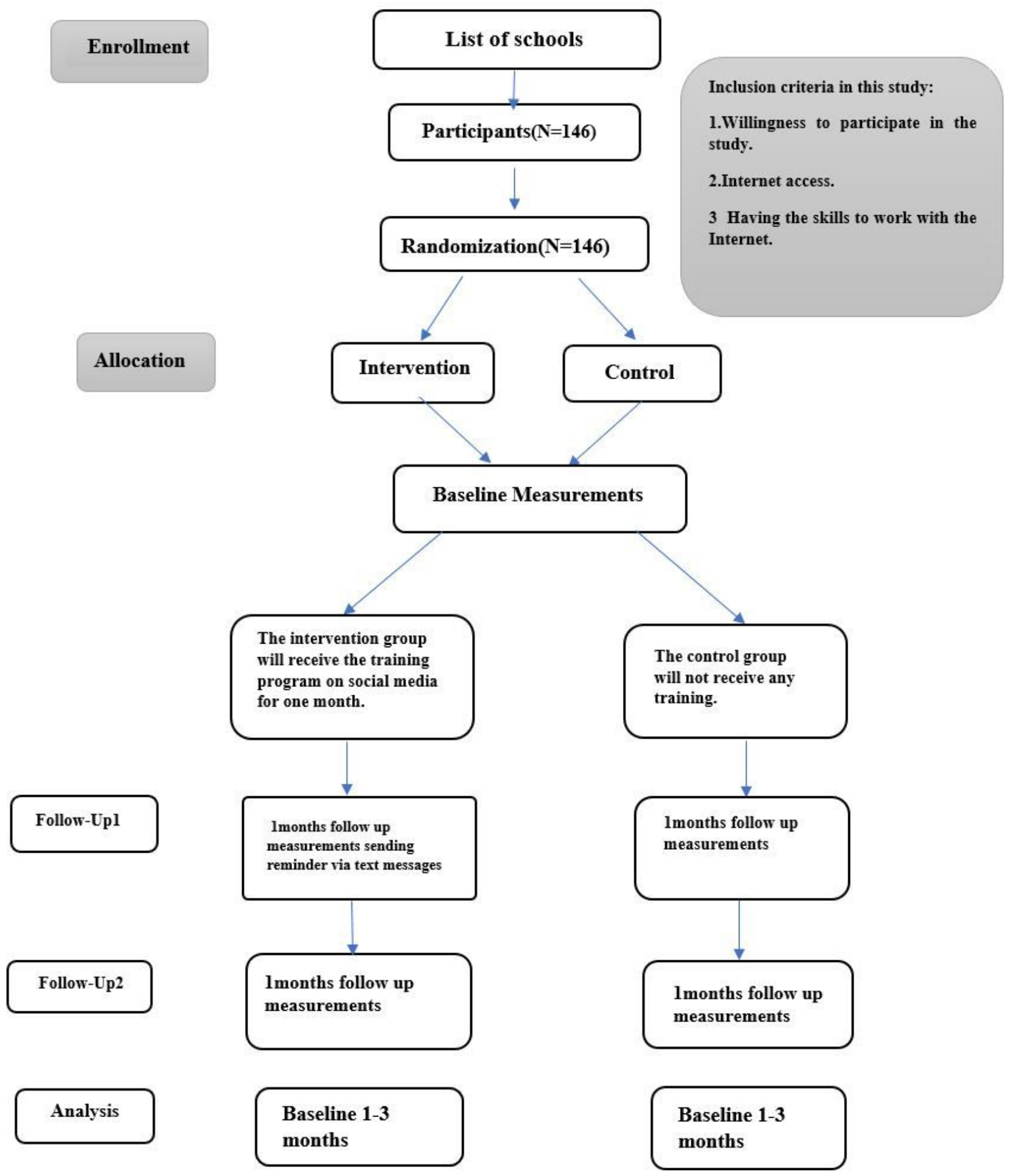

Figure 2

Consort flow diagram

\section{Supplementary Files}

This is a list of supplementary files associated with this preprint. Click to download. 
- Table1.jpg

Page $12 / 12$ 